\title{
PROTEÍNAS TIROSINA FOSFATASES: PROPRIEDADES E FUNÇÕES BIOLÓGICAS
}

\author{
Hiroshi Aoyama*, Telma Maria Araújo Silva, Márcio André Miranda e Carmen Veríssima Ferreira \\ Departamento de Bioquímica, Instituto de Biologia, Universidade Estadual de Campinas, CP 6109, 13083-970 Campinas - SP
}

Recebido em 9/1/03; aceito em 31/3/03

\begin{abstract}
PROTEIN TYROSINE PHOSPHATASES: PROPERTIES AND BIOLOGICAL FUNCTIONS. Protein phosphorylationdephosphorylation catalyzed by the opposing and dynamic action of protein kinases and phosphatases probably, is the most crucial chemical reaction taking place in living organisms. Protein phosphatases are classified according to their substrate specificity and sensitivity to inhibitory or activator agents, into two families of protein phosphatases: serine/threonine phosphatases and tyrosine phosphatases (PTPs). PTPs can be divided into 3 groups: tyrosine specific phosphatases, dual and low molecular weight phosphatases. The role of tyrosine phosphorylation in mitogenic signaling is well documented, and one would predict that vanadate, pervanadate and other oxidant agents (protein tyrosine phosphatase inhibitors) may act as a growth stimulator
\end{abstract}

Keywords: protein tyrosine phosphatases; signal transduction; biological function.

\section{INTRODUÇÃO}

As fosfatases são hidrolases que utilizam como substratos fosfomonoésteres, as quais estão amplamente distribuídas na natureza, tendo sido encontradas em animais ${ }^{1}$, vegetais ${ }^{2}$ e em microorganismos $^{3}$. Estas enzimas são divididas em 3 grupos principais: fosfatases alcalinas, fosfatases ácidas e proteínas fosfatases ${ }^{4}$.

As fosfatases ácidas apresentam um $\mathrm{pH}$ ótimo para catálise em torno de 5,0 e utilizam como substratos compostos com baixa massa molecular (por exemplo, açúcares fosforilados). Contrastando com as fosfatases ácidas, as alcalinas apresentam um pH ótimo para catálise em torno de 9,0 e também atuam em substratos de baixa massa molecular relativa. No entanto, há necessidade de íons divalentes, como magnésio, cobalto ou manganês, para catálise. Outra diferença observada em relação às fosfatases ácidas é o mecanismo de reação, como proposto por Vicent e colaboradores ${ }^{5}$.

Fosfatase alcalina

$\mathrm{E}+\mathrm{ROPO}_{3}^{2-} \Leftrightarrow \mathrm{E} \cdot \mathrm{ROPO}_{3}^{2-} \stackrel{\mathrm{ROH}}{\Leftrightarrow} \mathrm{E}-\mathrm{PO}_{3}^{2-} \Leftrightarrow \mathrm{E} \cdot \mathrm{Pi} \Leftrightarrow \mathrm{E}+\mathrm{Pi}$

Fosfatase ácida

$\mathrm{E}+\mathrm{ROPO}_{3} \mathrm{H}_{2} \Leftrightarrow \mathrm{E} \cdot \mathrm{ROPO}_{3} \mathrm{H}_{2} \stackrel{\mathrm{ROH}}{\Leftrightarrow} \mathrm{E}-\mathrm{PO}_{3} \mathrm{H}_{2} \stackrel{\mathrm{H}_{2} \mathrm{O}}{\longrightarrow} \mathrm{E}+\mathrm{Pi}$

Durante a última década, tem sido feito considerável progresso na elucidação do controle de crescimento e regulação de células eucarióticas ${ }^{6}$. O balanço entre a fosforilação e a desfosforilação de proteínas é a base para o controle de diversos eventos biológicos disparados por efetores extracelulares, como hormônios, mitógenos, carcinógenos, citocinas, neurotransmissores, substâncias ou metabólitos tóxicos ${ }^{7}$. Em consequiência à ação destes efetores ocorre regulação da divisão, diferenciação, desenvolvimento e morte celular, regulação do metabolismo e expressão gênica, contração, transporte, locomoção celular, aprendizado e memória ${ }^{8-11}$.

Muitas vias de sinalização celular são reguladas por fosforilação/ desfosforilação de proteínas. A adição ou remoção do grupamento

\footnotetext{
*e-mail: aoyama@unicamp.br
}

fosfato de uma proteína, pode gerar um "motivo" de reconhecimento para interação proteína-proteína, controle da estabilidade protéica e, o mais importante, modular atividade de enzimas ${ }^{12}$. Aproximadamente $30 \%$ das proteínas celulares são fosfoproteínas ${ }^{13}$.

Em células eucarióticas, a maioria da fosforilação de proteínas ocorre em resíduos de tirosina, serina e treonina, catalisada por proteínas quinases ${ }^{14}$. Dentre os diversos tipos de proteínas quinases, as proteínas tirosina, as serina/treonina quinases (proteína quinase dependente de AMPc, proteína quinase $\mathrm{C}$ (PKC) e proteínas quinases ativadas por mitógenos) participam de várias vias de transdução de sinais $^{15}$

Historicamente, proteínas tirosina fosfatases constituem uma grande família de enzimas com analogia às proteínas quinases em sua complexidade e diversidade estrutural. Portanto, estudos genéticos e bioquímicos mostraram que estas proteínas exercem efeitos tanto regulando negativamente, como positivamente, as vias de sinalização e no controle fisiológico de uma variedade de tecidos ${ }^{16}$. Mudanças anormais na atividade dessas enzimas acarretam na fosforilação inapropriada de resíduos de tirosina, o que contribue para o desenvolvimento de várias patologias, como neoplasias, diabetes e doenças resultantes de defeitos imunológicos ${ }^{17}$. Numa transformação oncogênica ou estimulação de fatores de crescimento, o nível de proteínas fosforiladas em resíduos de tirosina aumenta de 1-2\% na célula, podendo levar a graves doenças, incluindo o câncer ${ }^{12,18-20}$. Diversos autores têm trabalhado sistematicamente na compreensão destes fenômenos e vários trabalhos e revisões sobre o assunto estão disponíveis ${ }^{21-30}$.

Com base na função, estrutura, seqüência, especificidade, ativadores e inibidores, as proteínas fosfatases podem ser agrupadas em dois grandes grupos: proteínas serina/treonina fosfatases e proteínas tirosina fosfatases ${ }^{4,7,16}$.

As proteínas serina/treonina fosfatases compreendem duas famílias de genes chamados PPP e PPM. As proteínas fosfatases desta subfamília compreendem a família PPP de proteína Ser/Thr fosfatases, que se divide em seis subtipos PP1, PP2A, PP2B, PP4, PP5 e PP7, baseados nas suas características bioquímicas, sensibilidade a inibidores e substratos específicos ${ }^{31}$. A proteína serina/treonina PP2C é a única pertencente à família $\mathrm{PPM}^{32}$.

O principal tipo de serina/treonina fosfatase é a PP1, com peso molecular de $37 \mathrm{kDa}$, tem um importante papel em vários processos 
celulares do ponto de vista genético, farmacológico e bioquímico. Mutações na PP1 levam a defeitos na mitose, meiose, integridade celular e no metabolismo do glicogênio ${ }^{33}$.

A proteína fosfatase 2A (PP2A) exibe uma sequiência homóloga com a PP1 e é importante na regulação de eventos durante o início da mitose e inibição da fusão de vesículas endocíticas. Representa pouco mais de $1 \%$ das proteínas celulares totais e é responsável pela principal atividade das serina/treonina fosfatases, juntamente com a $\mathrm{PP} 1^{4}$. A regulação direta da atividade da PP2A está associada com a integridade do citoesqueleto e tanto esta enzima como a PP1 participam na modulação da motilidade celular, diferenciação e citocinese. Possui um importante papel em doenças parasitárias, virais, neurodegenerativas e no câncer ${ }^{34}$. As proteínas serina/treonina PP1 e PP2A participam da regulação da proteína quinase dependente de cálcio/ calmodulina ${ }^{4}$.

A calcineurina (PP2B) é uma enzima regulada por cálcio/ calmodulina, encontrada em tecidos celulares, dendritos, axônios e áreas do cerebelo ${ }^{35}$.

A PP2C é uma proteína monomérica $(42-45 \mathrm{kDa})$, a qual requer magnésio para sua atividade catalítica e consiste de duas isoformas, $\mathrm{PP}_{2} \mathrm{C}_{1}$ e PP2 $\mathrm{C}_{2}$. Participa da resposta celular ao estresse e é encontrada nos grânulos de células do cerebelo, hipocampo e possue larga distribuição em todo o cérebro ${ }^{36}$.

A PP4 é um membro da subfamília PP2A devido à sua homologia de $65 \%$ com a estrutura da PP2A. É encontrada no centrômero, núcleo e citoplasma, possuindo múltiplas funções, dentre elas, duplicação do centrômero ${ }^{37}$.

A PP5 é uma serina/treonina fosfatase que possui homologia catalítica com a calcineurina (PP2B) e com as proteínas serina/ treonina fosfatases PP1A e PP2A. É encontrada praticamente em todos os tecidos, principalmente no núcleo e a PP6 tem um papel na regulação da transcrição ${ }^{4}$.

Neste artigo de revisão daremos ênfase às proteínas tirosina fosfatases.

\section{PROTEÍNA TIROSINA FOSFATASE}

As proteínas tirosina fosfatases (PTPs) são uma grande família de enzimas (> 100) responsáveis pela hidrólise do fosfato ligado a resíduos de tirosina em proteínas. São estruturalmente diversas, incluindo a tipo citoplasmática e tipo receptor com a capacidade de transmitir sinais diretamente a enzimas de membrana e citoplasma, controlando diversos processos celulares ${ }^{12}$.

As proteínas tirosina fosfatases são caracterizadas por aproximadamente 240 aminoácidos e possuem um domínio altamente conservado com uma seqüência consenso no sítio catalítico característico desta família ([I/V]HCXAGXXR[S/T]G), onde I - isoleucina, V - valina, H - histidina, C - cisteína, A - alanina, G - glicina, R arginina, $\mathrm{S}$ - serina, $\mathrm{T}$ - treonina e $\mathrm{X}$ - qualquer aminoácido, compartilhando um padrão de sítio ativo constituído de uma cisteína e uma arginina, que são essenciais para a catálise enzimática. A presença da cisteína (C) no sítio ativo é responsável pela característica co- mum das proteínas tirosina fosfatases, que é a de serem inibidas pelo pervanadato, p-cloromercuribenzoato e outros agentes oxidantes s,38-40. $^{6}$. As estruturas tridimensionais de aproximadamente uma dúzia de PTPs têm sido determinadas, e têm ajudado a entender a função da PTP a nível molecular, por definir as interações que estabilizam a estrutura do sítio ativo e a formação do complexo enzima-substrato ${ }^{16}$.

Estudos bioquímicos e genéticos indicam que PTPs exercem efeitos positivos e negativos nas vias de sinalizações e participam de papéis fisiológicos cruciais em uma variedade de células e tecidos de mamíferos ${ }^{20}$. Uma única PTP pode regular múltiplas vias de sinalização, ou uma via chave pode ser regulada por diversas PTPs ${ }^{41}$.

Com base na função, estrutura e sequiência, as proteínas tirosina fosfatases podem ser agrupadas em três famílias principais: proteínas tirosina fosfatases específicas; proteínas fosfatases com dupla especificidade e proteínas fosfatases de baixa massa molecular relativa $^{7,42}$. Estas famílias apresentam regiões de consenso na seqüência de aminoácidos, principalmente do sítio ativo, os quais são resumidos na Tabela 1.

\section{Proteínas tirosina fosfatases específicas}

Estas enzimas hidrolisam resíduos Tyr-P alvos, são as enzimas melhor estudadas na superfamília das PTPs e apresentam alta massa molecular relativa (AMr). Estão envolvidas em várias de vias de sinalização e, nos últimos anos, mais de 112 PTPs foram isoladas e sequienciadas a partir de diversos organismos incluindo bactérias, leveduras, nematóides, insetos e vertebrados. Todas apresentam um domínio catalítico de aproximadamente 240 resíduos de aminoácidos, dos quais 71 são altamente conservados. Esta família é ainda subdividida em dois grupos: proteínas tirosina fosfatases tipo receptor e citoplasmáticas $^{28}$. Foram relatadas as estruturas cristalinas dos domínios catalíticos de três PTPs, determinadas por raios X: a PTP $\alpha$ tipo-receptor humana ${ }^{43}$, a PTP $1 \mathrm{~B}$ citoplasmática humana ${ }^{44}$ e a fosfatase da Yersinia ${ }^{28,45}$. As estruturas apresentam em comum 7 folhas $\beta$ torcidas e flanqueadas por oito $\alpha$-hélices, tendo na porção central a alça contendo o padrão $\mathrm{Cx}_{5} \mathrm{R}$. $\mathrm{O}$ alto grau de similaridade entre estas diferentes PTPs sugere que todos os membros desse subgrupo sejam muito parecidos ${ }^{28}$.

As PTPs tipo receptor (CD45, PTP $\alpha$ e PTP $\gamma$ ) são enzimas modulares, consistindo de um segmento extracelular, caracterizado pela presença de motivos semelhantes àqueles presentes em domínios de moléculas de adesão, como fibronectina, estando, portanto, envolvidas na comunicação célula-célula e transdução de sinal ${ }^{35,46}$; seguido de um segmento transmembranar simples e um ou dois domínios catalíticos intracelulares.

As PTPs citossólicas (PTP 1B ,VH1 e SHP) freqüentemente contém domínios extra catalíticos, que podem estar envolvidos diretamente na regulação da atividade catalítica ou servem no endereçamento e reconhecimento do substrato. Por exemplo, as PTPs SHP1 e SHP-2 possuem um par de domínios SH2 responsáveis pela ligação com proteínas contendo tirosina fosforilada, incrementando sua capacidade catalítica; as PTP 1B e a PTP da célula T possuem seg-

Tabela 1. Sequiência de consenso do sítio ativo para os três principais subgrupos na superfamília das tirosina fosfatases

\begin{tabular}{llllr}
\hline Subgrupo & Ácido geral & & Padrão do sítio ativo & Seqüências conhecidas \\
\hline PTP (específica) & sWPDh & $\mathrm{x}_{24}$ & PIVVHCSAGvGRTG & 103 \\
Cdc25 (dual) & yIIDC & $\mathrm{x}_{40}$ & IiVFhCEFSseRGP & 22 \\
PTP de BMr & dIeDP & $\mathrm{x}_{-95}$ & SVlfVClGNiCRSP & 14 \\
\hline
\end{tabular}

As letras em maiúsculas representam os resíduos altamente conservados (90\% das seqüências possuem o resíduo idêntico ou um aminoácido similar). O número $\mathrm{x}_{\mathrm{n}}$ refere-se ao número de resíduos de aminoácidos entre o ácido geral e o sítio ativo; nas PTPs de BMr, o ácido geral vem após a alça do sítio ativo na sequiência de aminoácidos, sendo indicado pelo número negativo. 
mentos C-terminal hidrofóbicos, que restringem a localização da enzima à região do retículo endoplasmático ${ }^{28,30}$. As PTPs podem ainda sofrer fosforilação do domínio não catalítico, causando modificações na atividade catalítica ou na localização celular ${ }^{47}$.

Outra característica marcante das PTPs é a capacidade de hidrolisar 100.000 vezes mais rápido a fosfotirosina do que a fosfoserina ou fosfotreonina. Isto se deve possivelmente à presença de resíduos de aminoácidos próximos ao sítio ativo, criando uma "bolsa", dentro da qual somente a fosfotirosina pode penetrar e sofrer a hidrólise; esta região (resíduos de 43-46, KNRY) é denominada "região de reconhecimento da fosfotirosina ${ }^{41,48}$.

\section{Proteínas tirosina fosfatases com dupla especificidade}

São capazes de hidrolisar fosfatos monoésteres de peptídeos contendo fosfotirosina e fosfoserina/treonina, possuindo mais afinidade por fosfotirosina, e esta característica dual parece estar associada à menor profundidade do sítio ativo de, aproximadamente, $6 \AA$ nas PTPs de especificidade dual e $9 \AA$ nas PTPs específicas. Essas enzimas participam da regulação de sinais mitogênicos e desempenham um papel importante no controle do ciclo celular (MKPs e cdc25) ${ }^{41}$.

\section{Proteínas tirosina fosfatases de baixa massa molecular relativa}

Estas enzimas não compartilham nenhuma homologia de sequiência com qualquer outra PTP, exceto pelo padrão de sítio ativo e mesmo mecanismo de catálise. Hidrolisam resíduos de tirosina e possuem um importante papel na regulação da proliferação celular, uma vez que a alta expressão desta enzima inibe a proliferação de células normais e transformadas ${ }^{4,41}$. Um dos substratos fisiológicos desta enzima é o receptor do fator de crescimento derivado de plaqueta (PDGFR), o qual está ativo quando fosforilado ${ }^{49}$. A alta expressão da proteína tirosina fosfatase de baixa massa molecular levou à inibição da via de sinalização estimulada pelo fator de crescimento derivado de plaquetas (PDGF) e, portanto, inibição da divisão celular ${ }^{50}$. No entanto, quando a atividade catalítica desta enzima foi modificada, o PDGFR manteve-se ativado ${ }^{51}$.

Estudos cinéticos e estruturais detalhados das subfamílias das PTPs revelaram um mecanismo químico comum para reações catalisadas por estas enzimas (Figura 1). Além disso, as proteínas tirosina fosfatases possuem uma variedade estrutural de domínios, incluindo SH2 e domínios extracelulares ligantes ${ }^{4,12,16,41}$.

\section{ESTRUTURA PTP E MECANISMO CATALÍTICO}

Estudos cinéticos, mutação sítio-dirigida e identificação das estruturas das PTPs permitiram identificar a cisteína, a arginina e a asparagina como resíduos extremamente importantes para catálise ${ }^{52}$.

Estudos abordando os mecanismos das PTPs de Yersinia, PTP1B, VHR (dual específica) e fosfatase de baixa massa molecular relativa sugerem que todas PTPs compartilham um mecanismo comum para efetuar catálise, utilizando a cisteína do sítio ativo como um nucleófilo na formação de um intermediário tiofosforil (enzima-fosfato). O resíduo de arginina na sequiência assinatura tem função de se ligar ao substrato, estabilizando o estado de transição. Tanto a etapa de formação do complexo fosfoenzima, quanto a sua hidrólise são auxiliadas pelo ácido aspártico presente no sítio ativo (Figura 1) (1,53 $^{\text {. }}$

\section{REGULAÇÃO DA ATIVIDADE DAS PROTEÍNAS TIROSINA FOSFATASES}

\section{Fosforilação}

Um mecanismo geral da regulação da atividade PTP é através da

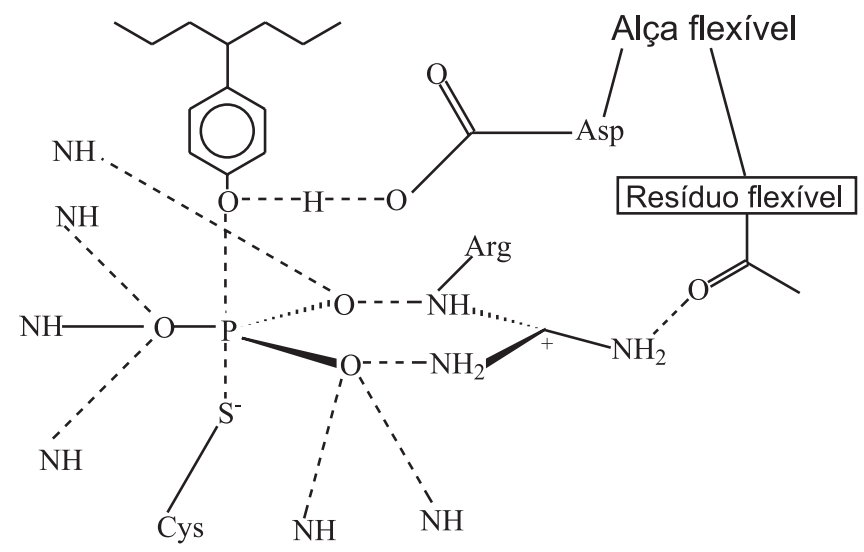

Figura 1. Mecanismo de catálise das proteínas tirosina fosfatases. Estado de transição para a transferência fosforil inicial do substrato para o resíduo de cisteína do sítio ativo da PTP. A alça PTP consiste de resíduos $(H / C) C$ $\left(X_{5}\right) R(S / T)$ na seqüência consenso. A arginina do sítio ativo tem função de ligação ao substrato e estabilização do estado de transição. $O$ resíduo ácido aspártico da alça flexível sofre mudança conformacional permitindo melhor interação da enzima com o substrato

fosforilação. A fosforilação de resíduos de serina/treonina específicos pode regular as PTPs, de modo negativo ou positivo. Tem sido descrita a ativação de várias PTPs pela fosforilação, incluindo PTP$1 \mathrm{~B}$ e SHP- ${ }^{47}$.

\section{Oxidação transiente}

A oxidação reversível da PTP é um mecanismo de regulação da atividade desta enzima. A inibição in vitro ocorre por vários oxidantes, incluindo $\mathrm{H}_{2} \mathrm{O}_{2}$, o qual atua como modulador oxidativo do resíduo de cisteína presente no sítio catalítico, causando alteração reversível deste resíduo, com produção do ácido sulfênico (Figura 2). Novas oxidações deste produto formado levam à produção dos ácidos sulfínico e sulfônico, que são produtos da oxidação irreversível ${ }^{54-56}$. O resíduo de cisteína presente no sítio catalítico também pode participar de outro mecanismo de regulação reversível, que é a formação de pontes dissulfeto, como ocorre com a cdc $25^{57}$.

A oxidação do resíduo de cisteína do sítio ativo pelo $\mathrm{H}_{2} \mathrm{O}_{2}$ tem sido identificada como um regulador negativo de $\mathrm{PTPs}^{58}$. $\mathrm{O} \mathrm{H}_{2} \mathrm{O}_{2}$ pode ser produzido depois da estimulação de vários RTKs, incluindo os receptores para fator de crescimento derivado de plaquetas (PDGF), fator de crescimento da epidermal (EGF), insulina e fator de crescimento de fibroblasto (FGF) ${ }^{59}$. Além do mais, a estimulação do receptor pelo EGF é correspondida por uma oxidação transiente da PTP1B ${ }^{58}$. A degradação do peróxido de hidrogênio pela catalase proveniente das células A431 reduziu drasticamente a fosforilação da tirosina de receptor EGF e Fosfolipase C. Similarmente, a expressão aumentada de catalase em células de músculo liso vascular bloqueou a indução da fosforilação do resíduo de tirosina da MAPK pelo receptor $\mathrm{PDGF}^{60}$. Esses efeitos da catalase indicam que a inibição de PTPs pelo $\mathrm{H}_{2} \mathrm{O}_{2}$ tem, também, um importante papel na sinalização via $\mathrm{RTK}^{61,62}$

Diferentes PTPs podem ser inibidas através da irradiação UV em células intactas. A geração de espécies reativas de oxigênio induzida por UV e subseqüente oxidação reversível de PTP(s) foi proposta como um mecanismo de regulação da atividade ${ }^{47}$.

\section{Dimerização}

A variabilidade estrutural dos domínios extracelulares de RPTPs 

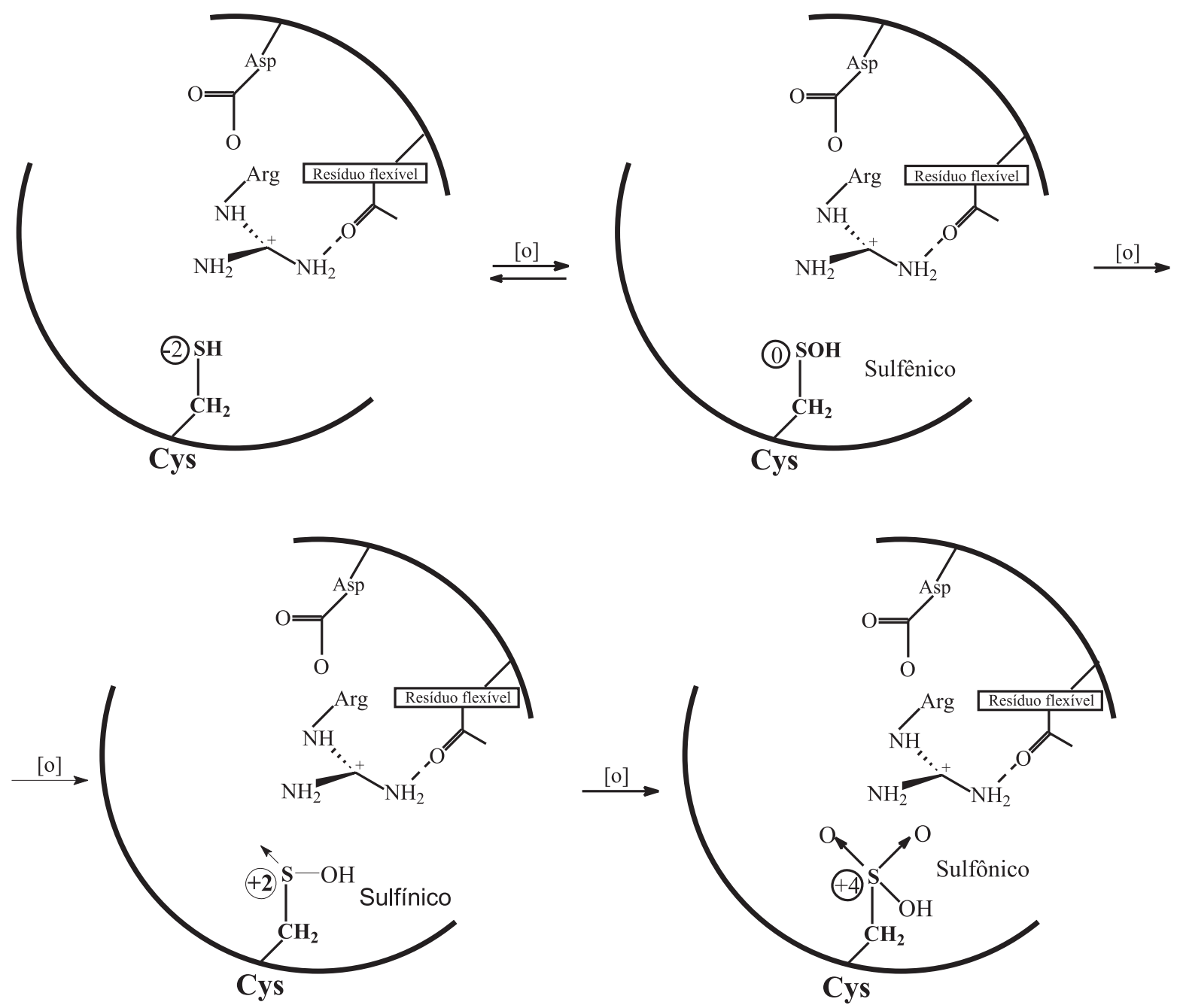

Figura 2. Reações de produção das formas oxidadas do resíduo de cisteína

sugere que os mesmos possam sofrer interações com ligantes seletivos, afetando potencialmente a atividade RPTP ${ }^{47}$. Portanto, ligantes extracelulares podem regular a atividade específica de RPTPs.

Estudos indicam que a dimerização pode inibir algumas RPTPs, como por exemplo, a inibição da CD45 pela dimerização induzida pelo EGF. Por outro lado, a dimerização de RPTK tem sido relacionada a uma perda de controle negativo de RTKs pelas PTPs, ou seja, uma resistência aumentada para desfosforilação $0^{47,63}$.

\section{Proteínas tirosina fosfatases como alvos terapêuticos}

A importância das PTPs na regulação de vários eventos celulares, qualifica-as como alvos terepêuticos para a descoberta de novas drogas $^{12}$. No entanto, devido à especificidade e ubiquidade destas enzimas, a inibição das mesmas pode ser inespecífica e, portanto, ter efeito sistêmico. A descoberta de um segundo sítio adjacente ao domínio catalítico na PTP1B, como proposto por Puius e colaboradores $^{64}$, proporcionou uma nova estratégia para aquisição de inibidores potentes e específicos para estas fosfatases ${ }^{12,41}$.

\section{REFERÊNCIAS}

1. Granjeiro, J. M.; Tese de Mestrado, Universidade Estadual de Campinas, Brasil, 1994.

2. Ferreira, C. V.; Granjeiro, J. M.; Taga, E. M.; Aoyama, H.; Plant Sci. 1999, $147,49$.
3. González, F. J.; Fauste, C.; Burguillo, F. J.; Dominguez, A.; Biochim. Biophys. Acta. 1993, 1162, 17.

4. Harrison, S.; Page, C. P.; Spina, D.; Gen. Pharmacol. 1999, 32, 287.

5. Vicent, J. B.; Crowder, M. W.; Averill B. A.; Trends Biochem. Sci. 1992, $17,105$.

6. Tonks, N. K.; Neel, B. G.; Cell 1996, 87, 365.

7. Jia, Z.; Biochem. Cell. Biol. 1997, 75, 17.

8. Cohen, P.; Annu. Rev. Biochem. 1988, 234, 115.

9. Johnson, L. N.; Barford, D.; Annu. Rev. Biophys. Biomol. Struct. 1993, 22, 199.

10. Trowbridge, I. S.; J. Biol. Chem. 1991, 266, 23517.

11. Genoux, D.; Haditsch, U.; Knobloch, M.; Michalon, A.; Stormt, D.; Mansuy, I. M.; Nature 2002, 418, 970.

12. Zhang, Z. Y.; Pharmacol. Toxicol. 2002, 42, 209.

13. Cohen, P.; Trends Biochem. Sci. 2000, 25, 596.

14. Bishop, A. C.; Buzko, O.; Shotak, M.; Trends Cell Biol. 2001, 11, 167.

15. Canno, E.; Mahdivan, L. C.; Trends Biochem. Sci. 1995, 20, 117.

16. Zhang, Z. Y.; Zhou, B.; Xie, L.; Pharmacol. Ther. 2002, 93, 307.

17. Hunter, T.; Cell 2002, 100, 113.

18. Neel, B. G.; Tonks, N. K.; Curr. Opin. Cell. Biol. 1997, 9, 193.

19. Kennedy, B. P.; Ramachandran, C.; Biochem. Pharmacol. 2000, 7, 877.

20. Li, L.; Dixon, J. E.; Semin. Immunol. 2000, 12, 75.

21. Pot, D. A.; Dixon, J. E.; Biochim. Biophys. Acta 1992, 1136, 35.

22. Cohen, P.; Trends Biochem. Sci. 1992, 17, 408.

23. Walton, K. M.; Dixon, J. E.; Annu. Rev. Biochem. 1993, 62, 101.

24. Krebs, E. G.; Trends Biochem. Sci. 1994, 19, 439.

25. Lenburg, M. E.; O'Shea, E. K.; Trends Biochem. Sci.1996, 21, 383.

26. Barford, D.; Trends Biochem. Sci. 1996, 21, 407.

27. Denu, J. M.; Stuckey, J. A.; Saper, M. A.; Dixon, J.E.; Cell 1996, 87, 361.

28. Fauman, E. B.; Saper, M. A.; Trends Biochem. Sci. 1996, 21, 413.

29. Ramponi, G.; Stefani, M.; Int. J. Biochem. Cell Biol. 1997, 29, 279. 
30. Byon, J. C.; Kenner, K. A.; Kusari, A. B.; Kusari, J.; Proc. Soc. Exp. Biol. Med. 1997, 216, 1

31. Mickey, C-T.; Jr-Wen, S.; Kathie, A. M.; Tse-Hua, T.; Gene 2001, $278,8$.

32. Sheppeck, J. E.; Gaus, C. M.; Chamberlin, A. R.; Bioorg. Med. Chem. 1997, $1739,50$.

33. Lin, Q.; Buckler IV, E. S.; Muse, S. V.; Walker, J. C.; Mol. Phyloge. Evol. 1999, 12, 57.

34. Sontag, E.; Cell. Signall. 2001, 13, 7.

35. Alexander, A.; Sem. Immunol. 2000, 12, 349.

36. Moore, F.; Weekes, J.; Hardie, D. G.; Eur. J. Biochem. 1991, 199, 691.

37. Brewis, N. D.; Street, A. J.; Prescott, A. R.; Cohen, P. T.; EMBO J. 1993, 12, 987.

38. Laidler, P. M.; Taga, E. M.; Van Etten, E. L.; Arch. Biochem. Biophys. 1982, $216,512$.

39. Huyter, G.; Liu, S.; Kelly, J.; Moffat, J.; Payette, P.; Kennedy, B.; Tsaprailis, G.; Gresse, M. J.; Ramachandran, C.; J. Biol. Chem. 1997, 10, 843.

40. Tracey, A. S.; J. Inorg. Biochem. 2000, 80, 11

41. Zhang, Z. Y.; Chem. Biol. 2001, 5, 416.

42. Fauman, E. B.; Yuvaniyama, C.; Schubert, H. L.; Stuckey, J. A.; Saper, M. A.; J. Biol. Chem. 1996, 271, 18780.

43. Bilwes, A. M.; Nature 1996, 382, 555.

44. Barford, D.; Flint, A. J.; Tonks, N. K.; Science 1994, 263, 1397.

45. Stuckey, J. A.; Schubert, H. L.; Fauman, E. B.; Zhang, Z-Y.; Dixon, J. E.; Saper, M. A.; Nature 1994, 370, 571.

46. Brady-Kalnay, S. M.; Rimm, D. L.; Tonks, N. K.; J. Cell Biol. 1995, 130, 977.

47. Östman, A.; Böhmer, D. F.; Trends Cell Biol. 2001, 11, 258.

48. Yuvaniyama, J.; Denu, J. M.; Dixon, J. E.; Saper M. A.; Science 1996, 272, 1328.
49. Heldin, C-H.; Östman, A.; Rönnstrand, L.; Biochim. Biophys. Acta 1998 , 1378,79 .

50. Berti, A.; Rigacci, S.; Raugei, G.; Deglinnocenti, D.; Ramponi, G.; FEBS Lett. 1994, 349, 7

51. Chiarugi, P.; Cirri, P.; Raugei, G.; Camici, G.; Dolfi, F.; Berti, A.; FEBS Lett. 1995, 372, 49

52. Zhang, M.; Zhou, M.; Van Etten, R. L.; Stauffacher, C. V.; Biochemistry 1997, 36, 15

53. Barford, D.; Biochem. Soc. Trans. 1999, 27, 751

54. Barrett, W. C.; DeGnore, J. P.; Keng, Y. J.; Keng, Y. F.; Zhang, Z.Y.; Yim, M. B.; Chock, P. B.; J. Biol. Chem. 1999, 247, 34543.

55. Callsen, D.; Sandau, K. B.; Brune, B.; Free Radical Biol. Med. 1999, 26, 1544.

56. Thomas, J. A.; Mallis, R. J.; Exp. Gerontol. 2001, 36, 1519.

57. Fauman, E. B.; Cogswell, J. P.; Lovejoy, B.; Rocque, W. J.; Holmes, W.; Montana, V. G.; Piwnica-Worms, H.; Rink, M. J.; Saper, M. A.; Cell 1998, 93, 617.

58. Lee, S. R.; J. Biol. Chem. 1998, 273, 15366.

59. Rhee, S. G.; Bae, Y. S.; Lee, S. R.; Lee, C.; FASEB J. 2000, 14, 11.

60. Bae, Y. S.; Kang, S. W.; Seo, M. S.; Baines, I. C.; Tekle, E.; Chock, P. B.; Rhee, S. G.; J. Biol. Chem. 1997, 272, 217.

61. Sundaresan, P.; Farndale, R. W.; FEBS Lett. 2002, 528, 139.

62. Bae, Y. S.; Sung, J. Y.; Kim, O. S.; Kim, Y. J.; Hur, K. C.; Kazlauskas, A.; Rhee, S. G.; J. Biol. Chem. 2000, 275, 10527.

63. Majeti, R.; Bilwes, A. M.; Noel, J. P.; Hunter, T.; Science 1998, $279,88$.

64. Puius, Y. A.; Zhao, Y.; Sullivan, M.; Lawrence, D. S.; Almo, S. C.; Zhang, Z. Y.; Proc. Natl. Acad. Sci. U.S.A. 1997, 94, 13420. 